\title{
The management of the colorectal cancer: Perspectives
}

\author{
Type of article: original \\ Boumediene Elhabachi, Morsli Doulat, Abderrahman Blaha, Soumia Zaouag, Hassan Cheheb \\ Faculty of medicine University of Sidi Bel Abbes, Algeria \\ CHU Dr Hassani A.E.K, Algeria
}

\begin{abstract}
Background: The progress of scientific research gives new tracks to be exploited for the management of the colorectal cancers whose the molecular profile study became fundamental. Aim: the aim of this study was to compare the management of the colorectal cancer in our patients to the current international recommendations.
\end{abstract}

Subjects and methods: In a retrospective study, we analysed 256 files between January, 2015 and September 2019. All the adenocarcinoma of colon and rectum were included.

Our patients were divided into two groups: 161 patients with colorectal cancer $(63 \%)$ and 95 patients with rectum cancer (37\%). We studied if the management of the disease was actually compliant to the international recommendations.

Results: Our study showed that the colorectal cancer occured most frequently in young population, with $45,5 \%$ in patients aged more than 60 years, $44 \%$ between $40-60$ years and 10 were under 40 years. The tumor was in T3 or more stage in $40,3 \%$ for colon cancer and 68,4\% for rectum cancer. Elsewhere, none of the patients benefited from a molecular profile study of his tumor.

Discussion:The colorectal cancer is diagnosed in relatively young population with $54,5 \%$ of patients aged less than 60 years among whom $10 \%$ are less than 40 , which explains the diagnostic delay. This delay is also due to the lack of a screening in general population and high risk subjects. Moreover, the absence of a molecular examination has a negative impact on the treatment and on the screening in the apparented, especially in case of tumor with micro satellite instability.

Conclusion: In order to improve the prognosis of the colorectal cancers in our patients, a screening adapted to the groups at risk has to be implemented and a molecular profil examination achived so that evolution and therapeutics perspectives could be set.

Keys words: colorectal cancer; molecular profile, management

Corresponding author: Boumedien Elhabachi, Faculty of medicine University of Sidi Bel Abbes, Algeria email: b.elhabachi@yahoo.fr

Received: July 12 2020. Reviewed: August 17 2020. Accepted: October 3 2020. Published: October 202020.

Medical Technologies Journal subscribes to the principles of the Committee on Publication Ethics (COPE).

Screened by iThenticate..@2017-2020 KNOWLEDGE KINGDOM PUBLISHING.

\section{Introduction}

Colorectal cancers (CRC) are common throughout the world with over 1 million cases and 500,000 deaths [1] per year. They occupy the third place among cancers [2]. However, the incidence of these cancers has decreased over the past four decades [3] particularly in the USA, thanks to endoscopic screening. It should be noted that it is the cancers of the left colon that have decreased while those of the right colon have remained stable. CRC is a serious disease due to its digestive location with its nutritional impact and its functional impact for cancers of the rectum, close to the anal sphincter. Adenocarcinomas (ADK) are the most common cancers on this segment of the digestive tract. This histopathological type is heterogeneous with a different therapeutic response and course. Immunohistochemistry and molecular biology have made it possible to define the different biological profiles of colorectal cancers, the mechanisms of carcinogenesis, the different signaling pathways, which has led to the development of increasingly effective targeted therapies. For proper management, it is essential to have certain informations, mainly the one concerning the presence of a mutation in one or more genes of the DNA mismatch repair system (MMR system). Indeed, adenocarcinomas presenting this abnormality are more frequent on the right colon; they are 
distinguished from left colon ADKs in terms of precancerous lesions, prognosis, epidemiology and response to medical treatment.

$5 \%$ of CRC are hereditary and 30\% occur in a context of family aggregation. In addition to an adequate epidemiological investigation, screening adapted to the risk group as well as the determination of the biological profile of the tumor should allow an effective management.

\section{Subjects and methods}

Through a retrospective study, we analyzed the files of 256 patients with CRC and treated in the general surgery department from January, 2015 to December, 2019.

Inclusion criteria: all colon cancers (CC) and rectum Cancers (RC) in both sexes treated in the adult surgical department.

Exclusion criteria: tumors of other histopathological types.

Our workforce consisted of 161 colon ADKs, 20 were admitted urgently in an occlusion picture and 95 rectal cancers. The predominance was slightly male and more pronounced for RC (Ratio 1.31). There are 88 men against 73 women for the $\mathrm{CCs}$ and 54 men against 41 women for the RC.

\section{For colon cancers:}

Age: only 12 cases were recorded in subjects under the age of 40 , ie $7 \%$ of colon cancers and $4.5 \%$ of all CRCs. The patients are over 60 years old in $52 \%$ of CCs (83 patients); $41 \%$ of patients (66 patients) are between 40 and 60 years old and $92 \%$ are over 40 years old.

The personal history: we find a notion of cancer in 8 patients and in 4 patients when assessing history familial; in 33 patients no history was specified.

Localization: we find 49 sigmoid localizations, 22 left colic ones, 19 transverse colic and 71 right colic ones, according to the files.

TNM classification: 54 patients presented with T3 tumors and 69 were T4.

Differentiation: 79 cancers are well differentiated, 30 moderately differentiated and 12 poorly differentiated. In 20 cases, the pathological study was imprecise.

All patients had an extension assessment with a total colonoscopy, apart from the patients urgently operated and 30 patients scheduled cold in whom colonoscopy was incomplete or impossible, mainly due to the evolutionary stage of the lesion and poor preparation.

For rectal cancers:

Age: 34 patients are over 60 years old (37.5\%), 47 patients between 40 and 60 years old $(51.5 \%)$ and 14 are under 40 years old.

Personal history : a personal history was found in 11 cases but no family one.

Localization: there were 35 cases on the lower rectum and an equal distribution for the middle and upper rectum.

Colonoscopy: was only possible in 55 patients.

TNM: 65 patients had T3 tumors or more.

Differentiation: ADK was well differentiated in 57 patients, moderately differentiated in 11 and poorly differentiated in 08 . In 10 cases the anatomopathology was inconclusive.

\section{Discussion}

In our series, relatively young and active subjects have the highest incidence of CRC. Through our analysis, it clearly appears that the diagnosis is most often late. Indeed, 
9.5\% of CRCs are admitted and operated on emergency, in an occlusion picture. This emergency concerns $12 \%$ of CCs and $4.5 \%$ of RC.

The diagnostic delay is confirmed by the pathological study. This delay in diagnosis is probably attributed to the occurrence of this cancer in a relatively young population which had been healthy until then, and without seriously affecting the general condition to get the patient and the physician attention. Regarding age, $45.5 \%$ of CRCs are diagnosed in subjects over 60 years old, $44 \%$ of patients were between 40 and 60 years old and $10 \%$ under 40 years old. RCs are developing in an increasingly younger population: $66.5 \%$ are under 60 years old. Elsewhere, this diagnostic delay also seems to be due to the location of the tumor. Indeed, and according to international epidemiological studies, $2 / 3$ of colonic cancers are located on the left colon knowing that the right colon concerns the segment going from the cecum to the splenic imprint, in other words, up to the left colic angle which is not included [4]. But in our series we find more ADK of the right colon (90 cases) than those of the left one (71 cases). These two locations are different, while patient records do not give great importance to such difference. The tumor location taken into account is surgical: etiopathogenically, the transverse colon does not exist, only the right colon and the left one are retained.

serrated polyps, more frequent precancerous lesions on the right, are difficult to identify by optical or virtual colonoscopy. Our analysis showed that no screening has been scheduled for first-degree relatives of these patients operated on for CRC, whereas a colonoscopy is required in these subjects becoming at high risk.

The diagnosis of CRC should no longer be based on clinical manifestations that are too often at an advanced stage, as the case is in our series. It is recommended by learned societies to offer screening in the general population said to be at average risk from the age of 50 years [5-8]. In the population at high risk, screening by optical endoscopy is necessary five years before the age of onset of cancer in the index case [9-11]. The same is true for chronic inflammatory bowel diseases that have progressed for 10 years with repeated flare-ups [12-14]. Syndromic cancers and polyposes are monitored by endoscopy according to the recommendations of learned societies [15].

Indeed, CRC is one of the best preventable cancers. This cancer almost always develops on benign lesions such as adenomatous and serrated polyps. The Adenoma - Cancer sequence is currently well established [16]. Adenomatous polyps are the precursors of the majority of colorectal cancers [16]. Up to $80 \%$ of colorectal cancers result from the malignant transformation of an adenomatous polyp with a first stage of genesis of the adenoma followed by its growth and then its malignant degeneration [17]. The risk of cancerization increases crescendo with size, the presence of a villous component and with the presence of severe dysplasia which is more common in villous polyps $[18,19]$. It is obvious that this risk of degeneration is greater when these risk factors are combined. These polyps are often the site of a Kras mutation.

Serrated polyps, more common on the right, are a heterogeneous group made up of three different entities with different potential for malignant development. According to the WHO classification, a distinction is made between the hyperplastic polyp, the sessile serrated adenoma and the traditional serrated adenoma [20-22]. The latter two have a potential for degeneration, particularly the sessile serrated adenoma which represents 15 to $20 \%$ of serrated polyps and $90 \%$ of these polyps are located in the right colon [23].It is currently recognized as being the initial lesion of colorectal carcinogenesis according to a new path called "the serrated path" $[21,22,24,25]$ often with a BRAF mutation [26]. 
Colorectal carcinogenesis is currently better known [27, 28] and three main molecular mechanisms of colorectal carcinogenesis are identified:

1- Chromosomal instability [29, 30], known as CIN (Chromosomal INstability) or LOH (Loss Of Heterozygoty). This pathway, involved in at least $80 \%$ of $\mathrm{CRC}$, is characterized by allelic losses associated with frequent mutations of tumor suppressor genes [30].

2- Micro satellite instability [29] Involved in about 15\% of CCRs. Cancers of the right colon are too often cancers with micro-satellite instability and called "MIS". This instability can be germinal by mutation of one of the genes of the MMR (Mismatch Repair) system or by methylation. If $15 \%$ of sporadic CRCs are of IMS phenotype (dMMR), almost all CRCs in Lynch syndrome will be of this phenotype. Numerous studies have shown that the IMS stage II and III phenotype has a better prognosis than MSS tumors [31, 32]. This prognostic factor seems to be of interest to all stages with a significant reduction in the risk of death $[33,34]$.

3 - Epigenetic instability $[21,35,36]$ is the third mechanism more recently described, but which is dependent on the first two ones [36]. Here, there is no mutation, no deletion, no chromosomal instability and no micro satellite instability by mutation of the genes of the MMR system. DNA is methylated by adding a methyl group to a cytosine base (CpG islands). The DNA sequence is nor altered neither modified; we are talking about epigenetic phenomenon and not genetic one. Depending on the number of markers or the degree of methylation, CIMP-H tumors (for high) and CIMP-L tumors (for low) are defined. CIMP-H tumors are often associated with a mutation in the BRAF proto-oncogene (V600E) [37]. This mutation is too often found in sessile serrated adenomas (SSA) which are the precursors of these tumors. Indeed, 90\% of tumors that develop from SSA have the BRAF mutation (V600E), whereas this mutation only very rarely [38]. or never [21] exists in adenomatous polyps.

These findings have clinical implications:

- It is important to look for the phenotype (dMMR), that is to say a lack of repair of DNA mismatches, and whose consequence is micro satellite instability and this by searching for protein extinction ("IHC" immunohistochemistry ) or by biological test. Among these tumors we should look for those belonging to Lynch syndrome defined by a mutation in one of the genes of the MMR system. In this case the patient and his relatives in the first degree become very high risk subjects requiring specific monitoring. The other tumors are unstable but sporadic. When IHC reveals a loss of expression of the MLH1 protein with or without PMS2 one, we must first look for a mutation of the BRAF gene and hypermethylation of the promoter of the MLH1 gene [39]. The presence of one of these abnormalities or of both of them indicates the sporadic character and the sequencing of the genes is no longer indicated saving time and money.

The search for the unstable MSI phenotype will be carried out in case of CRC in a subject aged less than 70 years or in case of several cancers belonging to the spectrum in patients or their first degree relatives [39, 40].

- The neoadjuvant treatment can be the cause of an extinction of the MSH6 protein without there being any micro-satellite instability.

- This same neoadjuvant treatment can give a complete histological response on an operative specimen. No test will be possible anymore. - The search for a BRAF and KRAS mutation is very important in case of metastatic colorectal disease in order to indicate a targeted therapy by anti EGFR (epidermal growth 
factor receptor) whose marketing authorization is conditioned by the absence of mutation [40].

- Tumors of the right colon with MSI phenotype and BRAF mutation have an excellent prognosis.

- On the other hand, colorectal tumors which develop along the serrated path, with CIMP-H methylation but MSS (satellite micro stability) are often diagnosed at an advanced stage.

- CRCs of the CIMP-H and MSS phenotype with BRAF mutation have a bad prognosis, in particular for stages II, III and IV [41, 42] with a higher risk of death.

- The MSI phenotype is rare in the rectum (about 3\%) which does not dispense from the same scientific rigor when it comes to defining the biological profile of the tumor.

- CRC at stage II and III IMS do not seem to benefit from chemotherapy with 5FU alone, unlike MSS CRC. This molecule, $5 \mathrm{FU}$, would even be deleterious for CRCs at stage II IMS. IMS would be predictive of the ineffectiveness of 5FU alone in CRC with sporadic IMS and not in Lynch syndrome tumors [43].

Determining the tumor IMS or MSS status has become essential to discuss the indication of adjuvant chemotherapy in a patient operated on for stage II CRC with bad prognostic factors.

In our patients, the diagnosis of CRC was made by anatomopathological study of biopsies obtained via endoscopy. Analysis of our files shows that the biopsies are limited to 3 samples on average and fixed with formalin. Taking into account the cited elements of modern oncology, it is imperative to obtain, in the future, 10 to 15 biopsies fixed and included in paraffin for molecular pathology. An immunohistochemical study or even a biological test looking for possible micro satellite instability must be carried out. The two tests are complementary.

\section{Conclusion}

The management of CRC requires specialists within a multidisciplinary team mastering the avenues of modern oncology. Treatment must be personalized. Each tumor has a specific biological profile. Immunohistochemical tests and molecular biology in addition to pathology data should allow a judicious therapeutic choice. This choice guarantees the best chances of recovery and survival for patients and allows us to spare them a heavy and expensive treatment and which is sometimes ineffective. The screening is the only way which allows a reduction of the mortality by colorectal cancer thanks to an early diagnosis as well as a reduction of the incidence of these tumors thanks to the diagnosis and treatment of pre cancerous lesions.

\section{Acknowledgment}

we would like to thank the general surgery team of the UHC of Sidi Bel Abbès, which allowed us the access to medical records in order to carry out this critical study.

\section{Conflict of interest statement}

We certify that there is no conflict of interest with any financial organization inthe subject matter or materials discussed in this manuscript. 


\section{Authors' biography}

Professor Boumédiène ELHABACHI: Gratuated in senology, cancerology and repair surgery. As a lecturer professor, I work hard and steadily to put implement any new techniques or actions within our hospital structures, that would allow us to open up to the future offered by onco-genetic advances and technologies of medical imagery. This will largery benefit the patients of tomorrow.

Doctor Hassan CHEHEB: Gratuated in general surgery. Assistant master, particularly invested in hepato-biliary cancerology, we are joining efforts to solve the problems of a future multidisciplinary management of our patients in a specific socio-economic and cultural context.

Doulat Morsli: Resident physicians general surgery faculty of medecine of sidi bel abbés.

Abderrahman Blaha: Resident physicians general surgery faculty of medecine of sidi bel abbés.

Soumia Zaouag: Resident physicians general surgery faculty of medecine of sidi bel abbés.

\section{References}

[1] Corrêa., R.d.S., et al., Rectal cancer survival in a Brazilian Cancer Reference Unit. JCOL, 2016. 36(4): p. 203-207. https://doi.org/10.1016/j.jcol.2016.04.015

[2] Wright, M., J.S. Beaty, and C.A. Ternent, Molecular Markers for Colorectal Cancer. Surg Clin North Am, 2017. 97(3): p. 683-701. https://doi.org/10.1016/j.suc.2017.01.014 PMid:28501255

[3] Siegel, R.L., et al., Colorectal cancer statistics, 2017. CA Cancer J Clin, 2017. 67(3): p. 177-193. https://doi.org/10.3322/caac.21395 PMid:28248415

[4] [Consensus conference: Prevention Screening and Management of the Colonic Cancers. Paris, France, January 29-30, 1998. Proceedings]. Gastroenterol Clin Biol, 1998. 22(3 Suppl): p. S1-295.

[5] Bibbins-Domingo, K., et al., Screening for Colorectal Cancer: US Preventive Services Task Force Recommendation Statement. JAMA, 2016. 315(23): p. 25642575. https://doi.org/10.1001/jama.2016.5989 PMid:27304597

[6] Moore, J.S. and T.H. Aulet, Colorectal Cancer Screening. Surg Clin North Am, 2017. 97(3): p. 487-502. https://doi.org/10.1016/j.suc.2017.01.001 PMid:28501242

[7] Winawer, S., et al., Colorectal cancer screening and surveillance: clinical guidelines and rationale-Update based on new evidence. Gastroenterology, 2003. 124(2): p. 544-60. https://doi.org/10.1053/gast.2003.50044 PMid:12557158

[1] Winawer, S.J., et al., Prevention of colorectal cancer by colonoscopic polypectomy. The National Polyp Study Workgroup. N Engl J Med, 1993. 329(27): p. 1977-81. https://doi.org/10.1056/NEJM199312303292701 PMid:8247072

[2] National Comprehensive Cancer Network. NCCN clinical practice guidelines in oncology (NCCN guidelines): colorectal cancer screening., 2018.

[3] National Comprehensive Cancer Network. Rectal Cancer. Version 3.2018., 2018.

[4] Kahi, C.J., et al., Colonoscopy Surveillance after Colorectal Cancer Resection: Recommendations of the US Multi-Society Task Force on Colorectal Cancer. Am J Gastroenterol, 2016. 111(3): p. 337-46; quiz 347. https://doi.org/10.1038/ajg.2016.22 PMid:26871541

[5] Devon, K.M., et al., Cancer of the anus complicating perianal Crohn's disease. Dis $\begin{array}{lllll}\text { Colon } & \text { Rectum, } & 2009 . & 52(2): & \text { p. }\end{array}$ https://doi.org/10.1007/DCR.0b013e318197d0ad PMid:19279414

[6] Higashi, D., et al., Cancer of the small intestine in patients with Crohn's disease. Anticancer Res, 2013. 33(7): p. 2977-80.

[7] Rutter, M.D., et al., Thirty-year analysis of a colonoscopic surveillance program for neoplasia in ulcerative colitis. Gastroenterology, 2006. 130(4): p. 1030-8. https://doi.org/10.1053/j.gastro.2005.12.035 PMid:16618396

[8] National Comprehensive Cancer Network.. NCCN Guidelines For Genetic / familial High-Risk Assessement: Colorectal., 2018. 
[9] Winawer, S.J., et al., Risk of colorectal cancer in the families of patients with adenomatous polyps. National Polyp Study Workgroup. N Engl J Med, 1996. 334(2): p. 82-7. https://doi.org/10.1056/NEJM199601113340204 PMid:8531963

[10] Takayama, T., et al., Aberrant crypt foci of the colon as precursors of adenoma and cancer. N Engl J Med, 1998. 339(18): p. 1277-84. https://doi.org/10.1056/NEJM199810293391803 PMid:9791143

[11] Eide, T.J., Risk of colorectal cancer in adenoma-bearing individuals within a defined population. Int J Cancer, 1986. 38(2): p. 173-6. https://doi.org/10.1002/ijc.2910380205 PMid:3733258

[12] Morson, B., President's address. The polyp-cancer sequence in the large bowel. Proc R Soc Med, 1974. 67(6 Pt 1$):$ p. $451-7$. https://doi.org/10.1177/00359157740676P115

[13] Bateman, A.C., Pathology of serrated colorectal lesions. J Clin Pathol, 2014. 67(10): p. 865-74. https://doi.org/10.1136/jclinpath-2014-202175 PMid:24561317

[14] Leggett, B. and V. Whitehall, Role of the serrated pathway in colorectal cancer pathogenesis. Gastroenterology, 2010. 138(6): p. 2088-100. https://doi.org/10.1053/j.gastro.2009.12.066 PMid:20420948

[15] Saito, S., H. Tajiri, and M. Ikegami, Serrated polyps of the colon and rectum: Endoscopic features including image enhanced endoscopy. World J Gastrointest Endosc, 2015. 7(9): p. 860-71. https://doi.org/10.4253/wjge.v7.i9.860 PMid:26240687 PMCid:PMC4515420

[16] Imai, K. and H. Yamamoto, Carcinogenesis and microsatellite instability: the interrelationship between genetics and epigenetics. Carcinogenesis, 2008. 29(4): p. 673-80. https://doi.org/10.1093/carcin/bgm228 PMid:17942460

[17] Longacre, T.A. and C.M. Fenoglio-Preiser, Mixed hyperplastic adenomatous polyps/serrated adenomas. A distinct form of colorectal neoplasia. Am J Surg Pathol, 1990. 14(6): p. 524-37. https://doi.org/10.1097/00000478-199006000-00003 PMid:2186644

[18] Torlakovic, E. and D.C. Snover, Serrated adenomatous polyposis in humans. $\begin{array}{lllll}\text { Gastroenterology, } & 1996 . & 110(3): & \text { p. } & 748-55 .\end{array}$ https://doi.org/10.1053/gast.1996.v110.pm8608884 PMid:8608884

[19] Bettington, M., et al., The serrated pathway to colorectal carcinoma: current concepts and challenges. Histopathology, 2013. 62(3): p. 367-86. https://doi.org/10.1111/his.12055 PMid:23339363

[20] Bae, J.M., J.H. Kim, and G.H. Kang, Molecular Subtypes of Colorectal Cancer and Their Clinicopathologic Features, With an Emphasis on the Serrated Neoplasia Pathway. Arch Pathol Lab Med, 2016. 140(5): p. 406-12. https://doi.org/10.5858/arpa.2015-0310-RA PMid:27128298

[21] Markowitz, S.D. and M.M. Bertagnolli, Molecular origins of cancer: Molecular basis of colorectal cancer. N Engl J Med, 2009. 361(25): p. 2449-60. https://doi.org/10.1056/NEJMra0804588 PMid:20018966 PMCid:PMC2843693

[22] Laurent-Puig, P., J. Agostini, and K. Maley, [Colorectal oncogenesis]. Bull Cancer, 2010. 97(11): p. 1311-21. https://doi.org/10.1684/bdc.2010.1216 PMid:21115420

[23] Vogelstein, B., et al., Genetic alterations during colorectal-tumor development. N $\begin{array}{lllll}\text { Engl J } & \text { Med, } & \text { 319(9): } & \text { 5. }\end{array}$ https://doi.org/10.1056/NEJM198809013190901 PMid:2841597

[24] Ribic, C.M., et al., Tumor microsatellite-instability status as a predictor of benefit from fluorouracil-based adjuvant chemotherapy for colon cancer. N Engl J Med, 2003. 349(3): p. 247-57. https://doi.org/10.1056/NEJMoa022289 PMid:12867608 PMCid:PMC3584639

[25] Sargent, D.J., et al., Defective mismatch repair as a predictive marker for lack of efficacy of fluorouracil-based adjuvant therapy in colon cancer. J Clin Oncol, 2010. 28(20): p. 3219-26. https://doi.org/10.1200/JCO.2009.27.1825 PMid:20498393 PMCid:PMC2903323

[26] Gryfe, R., et al., Tumor microsatellite instability and clinical outcome in young patients with colorectal cancer. N Engl J Med, 2000. 342(2): p. 69-77. https://doi.org/10.1056/NEJM200001133420201 PMid:10631274

[27] Popat, S., R. Hubner, and R.S. Houlston, Systematic review of microsatellite instability and colorectal cancer prognosis. J Clin Oncol, 2005. 23(3): p. 609-18. https://doi.org/10.1200/JCO.2005.01.086 PMid:15659508 
[28]Boland, C.R. and M. Shike, Report from the Jerusalem workshop on Lynch syndrome-hereditary nonpolyposis colorectal cancer. Gastroenterology, 2010. 138(7): p. 2197 e1-7. https://doi.org/10.1053/j.gastro.2010.04.024 PMid:20416305 PMCid:PMC3032350

[29] Colussi, D., et al., Molecular pathways involved in colorectal cancer: implications for disease behavior and prevention. Int J Mol Sci, 2013. 14(8): p. 16365-85. https://doi.org/10.3390/ijms140816365 PMid:23965959 PMCid:PMC3759916

[30] Stoffel, E.M. and C.R. Boland, Genetics and Genetic Testing in Hereditary Colorectal Cancer. Gastroenterology, 2015. 149(5): p. 1191-1203 e2. https://doi.org/10.1053/j.gastro.2015.07.021 PMid:26226567

[31] Jass, J.R., et al., Advanced colorectal polyps with the molecular and morphological features of serrated polyps and adenomas: concept of a 'fusion' pathway to colorectal cancer. Histopathology, 2006. 49(2): p. 121-31. https://doi.org/10.1111/j.1365-2559.2006.02466.x $\quad$ PMid:16879389 PMCid:PMC1619718

[32] Vasen, H.F., et al., Revised guidelines for the clinical management of Lynch syndrome (HNPCC): recommendations by a group of European experts. Gut, 2013. 62(6): p. 812-23. https://doi.org/10.1136/gutjnl-2012-304356 PMid:23408351 PMCid:PMC3647358

[33] Allegra, C.J., et al., American Society of Clinical Oncology provisional clinical opinion: testing for KRAS gene mutations in patients with metastatic colorectal carcinoma to predict response to anti-epidermal growth factor receptor monoclonal antibody therapy. J Clin Oncol, 2009. 27(12): p. 2091-6. https://doi.org/10.1200/JCO.2009.21.9170 PMid:19188670

[34] Samowitz, W.S., et al., Poor survival associated with the BRAF V600E mutation in microsatellite-stable colon cancers. Cancer Res, 2005. 65(14): p. 6063-9. https://doi.org/10.1158/0008-5472.CAN-05-0404 PMid:16024606

[35] Ward, R.L., et al., Adverse prognostic effect of methylation in colorectal cancer is reversed by microsatellite instability. J Clin Oncol, 2003. 21(20): p. 3729-36. https://doi.org/10.1200/JCO.2003.03.123 PMid:14551292

[36] Sinicrope, F.A., et al., DNA mismatch repair status and colon cancer recurrence and survival in clinical trials of 5-fluorouracil-based adjuvant therapy. J Natl Cancer Inst, 2011. 103(11): p. 863-75. https://doi.org/10.1093/jnci/djr153 PMid:21597022 PMCid:PMC3110173 